\title{
Effects of the Use of Smartphones on Pain and Muscle Fatigue in the Upper Extremity
}

\author{
Gyu Yong Kim, MS, PT ${ }^{1)}$, Chang SiK Ahn, PhD, $\mathrm{PT}^{2)}$, \\ Hye Won Jeon, MS, PT ${ }^{3)}$, Chang Ryeol Lee, PhD, PT ${ }^{3)}$ \\ 1) Cham Medical Hospital \\ 2) Department of Physical Therapy, Faculty of Health Science, Eulji University: 212 Yangji-dong, \\ Sujeong-gu, Seongnam-si, Gyeonggi-do 461-713, South Korea. TEL: +82 31-740-7232, E-mail: acsik@ \\ eulji.ac.kr \\ 3) Department of Physical Therapy, Korea Nazarene University
}

\begin{abstract}
Purpose] The purpose of this study was to investigate the effect of the use of smartphones on the upper extremity and determine whether there were differences in these changes between smartphone and computer use. [Subject] Forty healthy young adults (18 male, 25 female) took part in this study. [Methods] The pressure pain threshold measurement was assessed at the center of the upper trapezius of the dominant upper limb of the subjects. Electrodes were attached to the subjects in the two experiment groups, who then continuously performed a typing task on their own personal smartphone or computer keyboard for ten minutes. [Results] Regarding the pressure pain threshold of the upper trapezius, the smartphone and computer use groups showed significant decreases after performing the task compared with before it. Regarding muscle fatigue in the four monitored muscles, the smartphone and computer use groups showed deceases in median frequencies in all muscles measured after performing the tasks. The smartphone use group showed statistically significant differences in the brachioradialis, and the computer use group showed statistically significant differences in the upper trapezius when compared with the control group $(\mathrm{p}<0.05)$. [Conclusion] We found feasible relationships between smartphone use and musculoskeletal symptoms of the upper extremity and neck and identified physical differences between the smartphone use and computer use.

Key words: Smartphones, Pressure pain threshold, Muscle fatigue
\end{abstract}

(This article was submitted Jul. 3, 2012, and was accepted Aug. 2, 2012)

\section{INTRODUCTION}

In modern society, smartphones are one of the necessities for many people. The share of smartphones in the entire mobile phone market was $13.8 \%$ in 2009 and is expected to increase continuously to $24.9 \%$ by $2014^{1)}$. Along with the increase in the use of smartphones, the number of people who complain of xerophthalmia and carpal tunnel syndrome, etc., has been increasing, and the attention of the press and the clinical literature is being concentrated on the relationship between the use of smartphones and musculoskeletal system disorders $^{2}$. To send messages, search on the Internet, or use games or other functions on smartphones, the user must repeatedly press the screen. These repeated upper-extremity movements in static postures may induce uncomfortable feelings, pain, decreases in motor abilities, and contraction of disease ${ }^{3)}$. Raffle et al. ${ }^{4}$ ) indicated that repeated work of the upper extremity would not only cause minute damage to the muscles, joints, blood vessels, and nerves, but would also induce chronic pain and paresthesia in the neck, shoulders, arms, wrists, and fingers. A study by Ming et al. ${ }^{5)}$ found that upper extremity musculoskeletal system symptoms appeared in adults who used smartphones for long periods of time exceeding three years. In addition, several previous studies suggested that grabbing motions (motions of grabbing the mouse or smartphone), repeated pushing motions, and repeated movements of the thumb (e.g., piano playing or document entry) were risk factors that would induce upperextremity disorders ${ }^{6,7)}$. Berolo et al. ${ }^{2)}$ also pointed out that the use of smartphones was a potential risk factor that would threaten the health of the musculoskeletal system. Nevertheless, studies that have tested physical exposure related to the use of smartphones are lacking today ${ }^{2,3,8)}$. Therefore, it is necessary to evaluate the physical changes that occur during the use of smartphones, in particular, during repeated movements of pressing the screen, and determine whether their use is a risk factor that could induce musculoskeletal system disorders ${ }^{3)}$.

The purpose of this study was to investigate the effect of the use of smartphones requiring repeated motions on the upper-extremity musculoskeletal system and determine whether there are differences in these changes between smartphone use and computer use. 
Table 1. General characteristics of the subjects $(\mathrm{N}=40)$

\begin{tabular}{llccc}
\hline & & $\mathrm{SUG}(\mathrm{n}=15)^{\mathrm{a}}$ & $\mathrm{CUG}(\mathrm{n}=15)^{\mathrm{b}}$ & $\mathrm{CG}(\mathrm{n}=10)^{\mathrm{c}}$ \\
\hline Sex & Male (\%) & $4(27)$ & $8(53)$ & $5(50)$ \\
& Female (\%) & $11(73)$ & $7(47)$ & $5(50)$ \\
Age & & $21.67^{\mathrm{d}}$ & 22.87 & 22.20 \\
(years) & & $(2.09 ; 20-27)$ & $(1.51 ; 20-25)$ & $(0.79 ; 21-24)$ \\
Height & 164.47 & 169.00 & 168.30 \\
$(\mathrm{~cm})$ & & $(5.82 ; 155-175)$ & $(9.24 ; 154-186)$ & $(8.93 ; 160-183)$ \\
Weight & 55.60 & 60.40 & 60.40 \\
(kg) & & $(10.20 ; 43-85)$ & $(11.36 ; 45-79)$ & $(10.45 ; 47-76)$ \\
\hline
\end{tabular}

Note. ${ }^{a}$ SUG: Smartphone Use Group ${ }^{\mathrm{b}} \mathrm{CUG}$ : Computer Use Group ${ }^{\mathrm{c}} \mathrm{CG}$ : Control Group, ${ }^{\mathrm{d}}$ Mean (standard deviation; range), ${ }^{\dagger}$ Significant differences between groups by one-way ANOVA $(\mathrm{p}<0.05)$

\section{SUBJECTS AND METHODS}

\section{Subjects}

Forty-three healthy young adults (18 male, 25 female) were recruited for this study. Prior to testing, a pilot study was performed to established methods of noise reduction, reproducibility of measurements and data collection ${ }^{9}$. Participants were excluded if they had any history of upper extremity injury within the past year, visual problems, dizziness and vertigo, any deformity in the upper extremities or spine, previous history of surgery, or neurological or systemic disorders. They were also excluded if they had taken any sedative drug or alcohol within the past 48 hours $^{10,11)}$, and due to the above reasons, three of the subjects were excluded from the study. Written informed consent was obtained from each subject, and the study obtained approval from the local research ethics committee.

\section{Methods}

Subjects were randomly assigned into one control and two experimental (smartphone use and computer use) groups. The subjects sat in an erect posture (adducted shoulder girdles) on a chair without armrests and placed their back against the chair back, with the hips and knees flexed at $90^{\circ}$, shoulders neutrally rotated, and elbows flexed at $90^{\circ 9}$ ).

Prior to starting the experiment, the pressure pain threshold measurement was assessed at the center of the upper trapezius of the dominant upper limb of the subjects ${ }^{12)}$. Electrodes were attached to the subjects in the two experiment groups, who then continuously performed a typing task on their own personal smartphone or computer keyboard for ten minutes ${ }^{13)}$. All subjects typed at least 40 words per minute (wpm) using both hands and were not allowed to use the "delete" or "backspace" key.

The pressure pain threshold measurement was performed at the center of the upper trapezius ${ }^{12)}$. The investigator placed a digital pressure algometer (Commander ${ }^{\mathrm{TM}}$ Algometer, JTech Medical, Salt Lake City, UT, USA) on a site to be inspected and pressed against the tester in a vertical direction while increasing the force at a constant rate of $1 \mathrm{~kg} / \mathrm{cm}^{2}$. The investigator instructed the subjects to say "ouch" when only slight pain was felt. After measurement, the subjects were allowed to rest for five minutes. This procedure was repeated a total of three times.

The EMG signals for muscle fatigue analysis were recorded with a 16-channel surface EMG system (MyoSystem 1400A, Noraxon U.S.A. Inc., Scottsdale, AZ, USA). The EMG recordings were collected from four muscles of the dominant upper limb of the participants. The four muscles included the upper trapezius (UT), brachioradialis (BR), flexor carpi ulnaris (FCU), and abductor pollicis brevis (APB). A ground reference electrode was placed at the medial condyle on the dominant upper limb. The skin was prepared by cleaning it with alcohol and abrading with light sandpaper to reduce skin impedance ${ }^{14)}$. All raw EMG signals were analogue band-pass filtered between 20 and $350 \mathrm{~Hz}$, band-stop filtered at 60,120 , and $180 \mathrm{~Hz}$ to reduce noise, and sampled at a rate of $1000 \mathrm{~Hz}$. Each recorded EMG signal was divided in intervals of $1 \mathrm{~s}$. The median frequency of the EMG power spectrum was calculated in the initial $30 \mathrm{~s}$ and final $30 \mathrm{~s}$ with fast Fourier transforms (FFT) using Noraxon's MyoResearch software v1.06.

Data were analyzed using the Statistical Package for Social Sciences (SPSS 16.0 for Window). The KolmogorovSmirnov and Shapiro-Wilk tests of normality were conducted before the analysis, and one-way ANOVA was used to compare the baseline demographic characteristics between groups. Paired t-tests were performed to identify statistically significant differences within groups between before and after the typing task for the continuous variables. The differences between groups were compared using one-way ANOVA and post hoc multiple comparison analysis using Bonferroni correction was performed to examine differences suggested by ANOVA. The significance level was chosen as 0.05 .

\section{RESULTS}

Demographic data for subjects are summarized in Table 1. There were no significant differences for any variances such as those for age, height, and weight between groups.

Regarding the pressure pain threshold of the upper trapezius, the smartphone use group showed a significant decrease between before and after the typing test $(64.23 \mathrm{~kg} /$ $\mathrm{cm}^{2}$ to $55.72 \mathrm{~kg} / \mathrm{cm}^{2}, \mathrm{p}=0.001$ ), and the computer use group also was showed a significant decrease between before and 
Table 2.

\begin{tabular}{|c|c|c|c|c|c|c|c|}
\hline & & \multicolumn{2}{|c|}{ SUG $(n=15)$} & \multicolumn{2}{|c|}{ CUG $(n=15)$} & \multicolumn{2}{|c|}{$\mathrm{CG}(\mathrm{n}=10)$} \\
\hline & & Before & After & Before & After & Before & After \\
\hline \multirow{4}{*}{$\begin{array}{c}\mathrm{M} \\
\mathrm{D} \\
\mathrm{F}^{\mathrm{a}} \\
(\mathrm{Hz})\end{array}$} & $\mathrm{UT}^{\mathrm{b}}$ & $\begin{array}{c}65.79^{\mathrm{f}} \\
(27.33)\end{array}$ & $\begin{array}{c}64.78 \\
(25.85)\end{array}$ & $\begin{array}{c}55.57 \\
(15.24)\end{array}$ & $\begin{array}{l}49.17^{\ddagger} \\
(9.54)\end{array}$ & $\begin{array}{l}100.63 \\
(69.23)\end{array}$ & $\begin{array}{l}102.73 \\
(67.29)\end{array}$ \\
\hline & $\mathrm{BR}^{\mathrm{c}}$ & $\begin{array}{c}90.73 \\
(14.88)\end{array}$ & $\begin{array}{l}84.21^{\$ \dagger} \\
(14.59)\end{array}$ & $\begin{array}{l}78.51 \\
(7.84)\end{array}$ & $\begin{array}{l}76.25^{\S} \\
(7.23)\end{array}$ & $\begin{array}{l}185.10 \\
(16.06)\end{array}$ & $\begin{array}{l}184.60 \\
(16.73)\end{array}$ \\
\hline & $\mathrm{FCU}^{\mathrm{d}}$ & $\begin{array}{c}75.89 \\
(25.98)\end{array}$ & $\begin{array}{c}73.79 \\
(23.68)\end{array}$ & $\begin{array}{c}80.06 \\
(14.80)\end{array}$ & $\begin{array}{c}75.52^{\S} \\
(16.88)\end{array}$ & $\begin{array}{l}178.10 \\
(24.73)\end{array}$ & $\begin{array}{l}175.00 \\
(25.42)\end{array}$ \\
\hline & $\mathrm{APB}^{\mathrm{e}}$ & $\begin{array}{c}86.15 \\
(14.24)\end{array}$ & $\begin{array}{c}84.23 \\
(14.81)\end{array}$ & $\begin{array}{c}79.70 \\
(14.33)\end{array}$ & $\begin{array}{c}78.41 \\
(14.88)\end{array}$ & $\begin{array}{l}153.37 \\
(52.39)\end{array}$ & $\begin{array}{l}151.40 \\
(49.62)\end{array}$ \\
\hline
\end{tabular}

Note. ${ }^{\mathrm{a}} \mathrm{MDF}$ : median frequency, ${ }^{\mathrm{b}} \mathrm{UT}$ : upper trapezius, ${ }^{\mathrm{c} B R}$ : brachioradialis, ${ }^{\mathrm{d}} \mathrm{FUC}$ : flexor carpi ulnaris, ${ }^{\mathrm{e}} \mathrm{APB}$ : abductor pollicis brevis ${ }^{\mathrm{f}}$ Mean (standard deviation). ${ }^{\S}$ Significant differences between before and after the typing task by paired t-test $(\mathrm{p}<0.05)$, $\dagger$ Significant differences between SUG and CG using Bonferroni correction with one-way ANOVA $(\mathrm{p}<0.05)$, ${ }^{\star}$ Significant difference between CUG and CG using Bonferroni correction with one-way ANOVA $(\mathrm{p}<0.05)$

after the typing test $\left(61.56 \mathrm{~kg} / \mathrm{cm}^{2}\right.$ to $\left.49.79 \mathrm{~kg} / \mathrm{cm}^{2}, \mathrm{p}=0.000\right)$ $(\mathrm{p}<0.05)$. However, there was no significant difference in the control group.

Regarding muscle fatigue in the four monitored muscles, comparison of the median frequencies between before and after the typing task showed that statistically significant decreases only appeared in the brachioradialis muscle in the smartphone use group and in the brachioradialis and flexor carpi ulnaris in the computer use group $(\mathrm{p}<0.05)$ (Table 2$)$. However, there was no significant difference in the control group before and after the typing test. Also the computer use group showed statistically significant differences in the upper trapezius and the smartphone use group showed statistically significant differences in the brachioradialis when compared with the control group $(\mathrm{p}<0.05)$ (Table 2$)$.

\section{DISCUSSION}

The present study attempted to investigated whether the use of smartphones is a risk factor that would lead to musculoskeletal disorders and examined changes in pain and muscle fatigue in the upper extremity occurring during the use of smartphones.

In the present study, both the smartphone and computer use groups showed significant decreases in the pressure pain threshold after performing typing task $(p<0.05)$. These results were consistent with the results of other previous studies that measured the pressure pain threshold in the necks and shoulders of computer workers $\left.{ }^{15}, 16\right)$ and the results of a study by Berolo et al. ${ }^{2)}$ where it was reported that the use of smartphones caused pain in users' necks, shoulders, and arms. Fischer ${ }^{17)}$ suggested that where the pressure pain threshold of a site differed by $2 \mathrm{~kg} / \mathrm{cm}^{2}$ or more, or was lower than the normal value, the site might be considered to be abnormal. In this study, the pressure pain threshold decreased by $2 \mathrm{~kg} / \mathrm{cm}^{2}$ or more in both of the two experimental groups but not in the control group, and thus the experimental groups can be considered to have had abnormal conditions. The continuous muscle contractions in the neck and upper extremities during the performance of the tasks resulted in microscopic damage to muscles. This led to accumulation of fluids and an increase in the pressure of tissue in intracellular and extracellular spaces ${ }^{18)}$. Theses finding agreed with our results that reduce the pressure pain threshold.

To examine the effect of performing task on muscle fatigue in the upper extremity by group, the median frequency of the EMG power spectrum was analyzed during the initial $30 \mathrm{~s}$ and final $30 \mathrm{~s}$. Spectrum variables obtained from the frequency areas of surface electromyography were used as an objective measurement of muscle fatigue. Gerdle $\mathrm{B}^{19)}$ indicated that the median frequencies are spectrum indexes that would best reflect frequency deviation and are commonly used in analysis of changes in motor units. A study by Vollestad ${ }^{20)}$ also showed that median frequencies would reflect the original nature of spectra reliably and consistently. Based on the results of several previous studies, we chose the median frequency as the variable for analysis of muscle fatigue. In the present study, the smartphone and computer use groups showed deceases in median frequencies in all muscles measured after performing tasks. Statistically significant decreases appeared in the brachioradialis muscle in the smartphone use group and in the brachioradialis muscle and the flexor carpi ulnaris muscle in the computer use group in comparisons between before and after the typing task $(\mathrm{p}<0.05)$. The computer use group showed statistically significant differences in the upper trapezius and the smartphone use group showed statistically significant differences in the brachioradialis when compared with the control group $(\mathrm{p}<0.05)$. In general, muscle fatigue is caused by work that requires repeated movement in static postures, and thus the median frequency of muscles also gradually decreases ${ }^{21)}$. The decreases in median frequencies that appeared in the results of the current study showed that the use of smartphones and computers requiring repeated motions induced upper extremity muscle fatigue. Greater static strain may be placed on the hand and arm muscles during mobile phone use as compared with during desktop or laptop use ${ }^{2)}$. Work involving intensive use of the hands, thumbs, and fingers with repeated, static, or extreme finger postures may lead to pain and discomfort, decreased performance, and sick leave ${ }^{5,22)}$. The forearm muscles are also 
closely related to the position and movement of the thumb, and these muscles are continuously stimulated during the use of smartphones; thus, related physical exposure may induce upper extremity musculoskeletal disorders ${ }^{5)}$. Therefore the extended intensive use of mobile phones could give rise to pain and musculoskeletal disorders in the upper extremity.

This study has several limitations: first, the number of study subjects was small, and thus there were difficulties in making generalizations; second, the measuring time was not long enough to induce fatigue in all muscles; and third, the smartphone and the computer use groups were not sufficiently controlled so that their work postures were completely the same. In the future, multilateral studies to examine the effect of the use of smartphones on the occurrence of upper extremity musculoskeletal disorders are necessary. Although this research is preliminary, we found feasible relationships between smartphones use and musculoskeletal symptoms of the upper extremity and neck and identified physical differences between the smartphone use and computer use. Further studies are needed focusing on a prospective study with more well-validated exposure measures, including a larger sample.

\section{REFERENCES}

1) Portio: Research: Smartphone Futures, 2009

2) Berolo S, Wells RP, Amick BC: Musculoskeletal symptoms among mobile hand-held device users and their relationship to device use. Appl Ergon, 2011, 42: 371-378. [Medline] [CrossRef]

3) Gustafsson E, Johnson PW, Hagberg M: Thumb postures \& physical loads during mobile phone use-a comparison of young adults with and without musculoskeletal symptoms. J Electromyogr Kinesiol, 2010, 20: 127-135. [Medline] [CrossRef]

4) Raffle AE, Mackenzie EF: Management of cervical dyskaryosis. No easy answer. BMJ, 1994, 309: 270. [Medline]

5) Ming Z, Pietikainen S, Hanninen O: Excessive texting in pathophysiology of first carpometacarpal joint arthritis. Pathophysiology, 2006, 13: 269-270. [Medline] [CrossRef]

6) Barr AE, Barbe MF, Clark BD: Work-related musculoskeletal disorder of the hand and wrist: epidemiology, pathophysiology, and sensorimoto changes. J Orthop Sports Phys Ther, 2004, 34: 610-627. [Medline]

7) Gupta $\mathrm{AD}$, Mahalanabis D: Study of hand function in a group of shoe factory workers engaged in repetitive work. J Occup Rehabil, 2006, 16 : 675-684. [Medline] [CrossRef]

8) Gold JE, Driban JB, Thomas N, et al.: Postures, typing strategies, and gender differences in mobile device usage: an observational study. Appl Ergon, 2012, 43: 408-412. [Medline] [CrossRef]

9) Alizadehkhaiyat O, Fisher AC, Kemp GJ, et al.: Shoulder muscle activation and fatigue during a controlled forceful hand grip task. J Electromyogr Kinesiol, 2011, 21: 478-482. [Medline] [CrossRef]

10) Sesto ME, Radwin RG, Best TM, et al: Upper limb mechanical changes following short duration repetitive eccentric exertions. Clin Biomech (Bristol, Avon), 2004, 19: 921-928. [Medline] [CrossRef]

11) Fuller JR, Lomond KV, Fung J, et al.: Posture movement changes following repetitive motion induced shoulder muscle fatigue. J Electromyogr Kinesiol, 2009, 19: 1043-1052. [Medline] [CrossRef]

12) Park G, Kim CW, Park SB, et al.: Reliability and usefulness of the pressure pain threshold measurement in patients with myofascial pain. Ann Rehabil Med, 2011, 35: 412-417. [Medline] [CrossRef]

13) Serina ER, Tal R, Rempel D: Wrist and forearm postures and motions during typing. Ergonomics, 1999, 42: 938-951. [Medline] [CrossRef]

14) Minning S, Eliot CA, Uhl TL, et al.: EMG analysis of shoulder muscle fatigue during resisted isometric shoulder elevation. J Electromyogr Kinesiol, 2007, 17: 153-159. [Medline] [CrossRef]

15) Roh SC, Lee SJ, Song JC, et al.: Association between myofascial pain syndrome and the assessment of pain and the related function tests in female telephone directory assistance operators using VDT. Korean J Prev Med, 1997, 30: 779-790.

16) Cho SG, Seo JC, Choi DY, et al.: Effects of acupuncture on upper back myofascial pain and pain pressure threshold. J Korean Acupunct Moxibustion Soc, 2001, 18: 1-10.

17) Fisher AA: Documentation of myofascial trigger points. Arch Phys Med Rehabil, 1988, 96: 286-291.

18) Hasson S, Mundorf R, Barnes W, et al.: Effect of pulsed ultrasound versus placebo on muscle soreness perception and muscular performance. Scand J Rehabil Med, 1990, 22: 199-205. [Medline]

19) Gerdle B., Henriksson-Larsen K, Lorentzon R, et al.: Dependence of the mean power frequency of the electromyogram on muscle force and fiber type. Acta Physiol Scand, 1981, 142: 457-465. [CrossRef]

20) Vøllestad NK: Measure of human muscle fatigue. Neurosci Methods, 1997, 74: 219-227. [CrossRef]

21) Kraemer WJ, Volek JS, Bush JA, et al.: Influence of compression hosiery on physiological responses to standing fatigue in women. Med Sci Sports Exerc, 2000, 32: 1849-1858. [Medline] [CrossRef]

22) Fontana L, Neel SC, Ughetto JM, et al.: Osteoarthritis of the thumb carpometacarpal Joint in women and occupational risk factors: a case-control study. J Hand Surg Am, 2007, 32: 459-465. [Medline] 